\title{
POTENCIALIdAdeS E LIMITAÇÕES DA METOdologia DE ANÁLISE DE REDE: UM MODELO TEÓRICO voltado PARA AS Cin̂nCIAs Sociais
}

\author{
Francisco Conrado Filho \& Luís António Santos
}

\begin{abstract}
Resumo
Este artigo procura discutir o lugar da análise de rede dentro das Ciências Sociais, não somente como uma simples ferramenta de investigação metodológica, mas também na perspetiva de um campo de investigação com teorias próprias e consolidadas. Enquadrar a sua utilização significa discutir o seu papel na análise e compreensão de objetos por um campo que sofre, às vezes, acusações de ser bastante tecnicista. Apesar de impulsionado pelas novas tecnologias de comunicação e pelos média sociais, em particular, a análise de rede tem um espectro de utilização muito mais alargado, pelo que pretendemos apresentar algumas das abordagens possíveis na investigação em Ciências Sociais. Por último, tratando-se de uma metodologia interdisciplinar por natureza, acautelamos alguns dos seus riscos e enviesamentos.
\end{abstract}

Palavras-chave

Análise de rede; Ciências Sociais; média sociais; metodologias

\begin{abstract}
This paper explores the potentialities and limitations of network analysis, not only as a methodological tool that may be used in Social Science research but also as a separate discipline, with its own well-tested theories. Providing a framework for the use of network analysis involves discussing the role that it can play in understanding objects using a field that is sometimes accused of being too technical. Despite the fact that it has increased in popularity over recent years, driven by new communication technologies and especially social media channels, network analysis has a much broader use, and we therefore aim to demonstrate some innovative approaches that may be used in Social Science research. Finally, because it is an interdisciplinary methodology, we discuss some of the associated risks and biases.
\end{abstract}

KeYwORDS

Methodologies; network analysis; social media; Social Sciences

\section{INTRODUÇÃo}

Novos tempos trazem novos desafios e com eles novas metodologias de investigação são criadas, reestruturadas ou simplesmente retomadas na tentativa de explicar determinada realidade. A metodologia de análise de rede é apenas mais um desses exemplos de reapropriação para explicar novos contextos, que acabou por crescer e criar o seu próprio campo de investigação. Longe de ser uma metodologia recente, a análise 
de rede veio a alcançar a sua maturidade ainda na década de 1970. Contudo, só na última década viu o seu alcance crescer exponencialmente por investigadores das mais diversas áreas, muito devido a dois fatores fundamentais: o acesso às ferramentas e a grande popularização do conceito de redes. É o que podemos depreender da defesa de Watts sobre a agora chamada Ciência das Redes:

impulsionado pelo rápido crescimento e disponibilização de computadores cada vez mais potentes e económicos, além da capacidade de armazenamento de base de dados de grande escala, investigadores das áreas da Matemática, Biologia e Ciências Sociais realizaram avanços substanciais no número de problemas até então intratáveis, reformulando ideias antigas, introduzindo novas técnicas e encontrando relações entre o que até então pareciam problemas completamente díspares. O resultado está a ser chamado de a nova Ciência das Redes. (2004, p. 243)

Para este artigo interessa-nos sobretudo centrar atenções no conceito de rede e na sua aplicação dentro do campo das Ciências Sociais. Tentaremos demonstrar que a análise das redes não é apenas uma mera ferramenta descritiva e quantitativa e, para esse fim, vamos resgatar conceitos da recente formulada Ciência das Redes.

Quem olhe para todo o aparato de ferramentas de análise de rede que existe hoje, muito dele vocacionado para o estudo dos média sociais, pode ficar com a impressão de que se trata de um campo muito mais ligado às Ciências Exatas do que às Ciências Sociais. O engano é compreensível, mas não sendo o nosso objetivo debruçar-nos aqui sobre a história da análise de rede, é importante apenas relembrar que essa metodologia nasceu no seio da Sociologia e da Antropologia, tendo sempre sido utilizada por esses domínios do saber para explicar a intricada teia de relações e influências sociais entre determinados atores e instituições. Apesar da aparência em contrário, a análise de rede está intimamente ligada às Ciências Sociais. É por isso que nos interessa discutir o seu papel e valor.

Ainda como nota inicial, é importante salientar que quando nos referimos a análise de rede no seu sentindo lato, ao invés da mais comum análise de rede social, é para evitar a ambiguidade que o termo gera com o conceito de redes sociais em português. As referidas redes sociais podem ser tanto as de natureza online como as baseadas na experiência observada do quotidiano. A explicação para a visão tecnicista do conceito de redes advém principalmente do facto de que, ao falar-se em redes sociais, muitos são levados a crer que estamos a falar de plataformas como Facebook, Twitter, Instagram e, por isso mesmo, atribuem uma conotação mais voltada para a tecnologia do que aquela que o termo realmente indica. Para evitar ambiguidades, quando nos referirmos às redes sociais online, utilizaremos o termo média social. Entre outras razões, por ser o termo mais adequado para explicar o papel que essas plataformas desempenham na dieta mediática. Já não só cumprem a função de criar laços sociais entre os utilizadores, como também são utilizadas para atividades paralelas (Amaral, 2012). Para uma melhor compreensão desse conceito, basta referir Fuchs: 
média social é um termo complexo que envolve diferentes camadas. O Facebook contém muito conteúdo (informação) e é também uma ferramenta para comunicação e para a manutenção e criação de comunidades. É apenas em menor grau uma ferramenta de trabalho colaborativo, mas envolve pelo menos três tipos de sociabilidade: cognição, comunicação e comunidade. $(2014$, p. 6)

Feito este esclarecimento, antes de adentrarmos na perspetiva de rede convém primeiro elucidar o seu conceito e discutir o que representam as redes exatamente.

\section{REDE SOCIAL: UM CONCEITO}

Rede, em última instância, pode ser entendida como sendo o contexto, isto é, toda a estrutura social que reúne os atores e as instituições que contribuem, competem ou convergem de certo modo para os eventos que estão a ser observados. Wasserman e Faust (1994) afirmam que, desde uma perspetiva de rede, toda a sociedade pode ser expressa como um conjunto de padrões e regularidades observadas no comportamento dos seus indivíduos. O termo rede abre, portanto, espaço para um grande número de representações distintas da realidade. Como fica patente na descrição de Serrat:

as redes sociais são nós de indivíduos, grupos, organizações e sistemas relacionados que se entrelaçam através de um ou mais tipos de interdependência: essas incluem valores partilhados, visões e ideias; contactos sociais; parentesco; conflito; transações comerciais; trocas; associação conjunta em organizações; além de participações de grupo em eventos, entre inúmeros outros aspetos das relações humanas. (2017, p. 39)

Para Molina (2009), a palavra rede é, inclusivamente, a representação metafórica perfeita da complexidade que envolve os atores sociais. Sendo, portanto, a sua representação visual não só obrigatória como o elo de aproximação entre a metáfora e o conceito estudado. Desde essa perspetiva, não nos é difícil perceber que todos os indivíduos integram redes de influência, estejam eles conscientes ou não, e as suas ações podem ser mais bem entendidas através da análise das suas relações do que através dos seus atributos individuais.

A ênfase dada à dinâmica das relações não é de agora. No século XIX, Émile Durkheim, um dos nomes basilares da Sociologia, concebia as sociedades como sistemas biológicos e que, como tal, poderiam ser estudadas através do padrão das relações que se originavam no seu seio (Borgatti, Mehra \& Labianca, 2009). Essas regularidades deveriam ser entendidas como as estruturas que possibilitariam a ação individual e, consequentemente, o estudo dos atributos dos indivíduos passaria antes pela compreensão da estrutura no qual se encontram inseridos.

O que parecia apenas como uma metáfora intuitiva passou décadas mais tarde a ser formalizada através da incorporação de elementos advindos da Teoria dos Grafos. Foi quando se passou a identificar características morfológicas das redes e se estabeleceu 
que estas estão intrinsecamente relacionadas com o comportamento dos seus indivíduos (Lemieux \& Ouimet, 2012).

Moreno será considerado aquele que primeiro concebeu a ideia de aplicar o estudo das redes para explicar o comportamento individual, naquilo que ficou conhecido como sociometria: uma técnica de visualizar graficamente as ligações, mesmo que subjetivas, entre os atores (Moreno, 1934). Desde então, o campo floresceu com a incorporação das matrizes, da já mencionada teoria dos grafos, como também de conceitos da Psicologia e Sociologia.

Foi no seguimento destas incorporações que o que era concebido apenas como uma metodologia, no sentido em que se tratava de um conjunto de procedimentos para a análise de um determinado objeto, passou a ser reconhecido como uma perspetiva teórica com as suas próprias formulações e os seus próprios conceitos e teorias. Foi importante o trabalho de autores como Watts e Strogatz (1998) na formulação do conceito de redes dinâmicas, ao afirmarem que as redes não apresentam comportamento ordenado ou aleatório, mas exibem importantes propriedades dos dois conceitos, sendo essas propriedades extrapoladas através de modelos matemáticos relativamente simples. Outro trabalho que veio refundar a visão acerca das redes foi o de Barabási e Albert (1999) e os modelos de escala livre e de ligação preferencial entre os atores, que passaram a ser conhecidos como a lei de potência [power law]. Esses conceitos, essencialmente matemáticos, encontram rapidamente lastro dentro das Ciências Sociais. Por exemplo, a lei de potência defende que as redes evoluem com base em princípios de ligação preferencial, ou seja, dentro de uma lógica do rico que fica cada vez mais rico, os nós mais populares tendem a atrair mais ligações do que outros. Aplicado às Ciências Sociais, encontramos uma ligação direta com o conceito de "capital social" (que mais adiante trataremos com mais pormenor).

São estes princípios partilhados entre os mais variados sistemas que levam diversos autores a afirmar que uma nova perspetiva teórica está a ser desenvolvida (Barabási, 2002; Buchanan, 2002; Watts, 2003). Uma perspetiva não confinada apenas ao estudo dos objetos matemáticos, mas também dos organismos biológicos e das organizações sociais. Uma ideia que, como já demonstrámos, retrocede a Durkheim.

Barabási (2016) segue nessa mesma linha ao afirmar que a chave para a descoberta da Ciência de Rede advém do facto de que a arquitetura das redes, a emergir nos mais diferentes domínios da ciência, prova de que estas são governadas pelos mesmos princípios organizadores e, portanto, são passíveis de partilharem as mesmas ferramentas de exploração matemática.

Com isso podemos perceber que o termo rede serve para descrever tanto as comunidades indígenas, os agregados urbanos, as plataformas de partilha online, como uma instalação elétrica e a malha ferroviária de um país. Foi esta maleabilidade do conceito que conferiu à ideia de rede a sua vocação interdisciplinar. A fácil representação gráfica através de pontos e traços dá-se ao uso dos mais variados sistemas: um ator social, uma instituição, uma bactéria, um apeadeiro. Para não mencionarmos a conversão desses elementos em categorias mais genéricas, algo que será discutido mais adiante no texto. 
Consequentemente, sempre que houver alguma relação de interdependência entre os objetos analisados, a perspetiva de rede poderá ser aplicada. A questão torna-se ainda mais relevante quando saímos do campo das aplicações matemáticas e trabalhamos as perspetivas teóricas que informam a construção de uma rede, como é o caso da construção das identidades, dos princípios de transitividade, da homofilia, dos buracos estruturais e da teoria do mundo pequeno, entre outras.

\section{REDE SOCIAL: UMA PERSPETIVA}

Por muito que se discuta se a perspetiva de redes será apenas uma metodologia com pretensões de novo campo do conhecimento, alguns elementos contribuem para a constatação de que não estamos apenas diante de um conjunto elaborado de técnicas para análise de um determinado fenómeno. Borgatti, Mehra e Labianca (2009) identificam que essas críticas não são de agora e baseiam-se em dois pontos: a falta de teorias próprias e um carácter essencialmente descritivo.

Antes de mais, a acusação de falta de teorias nativas não somente é errónea como não reconhece o papel crucial que muitas destas teorias exerceram na explicação de diversos fenómenos. Segundo, pelo facto de que o pedir de empréstimo teorias e conceitos de outros campos, em última instância, demonstra o papel transdisciplinar e, portanto, o reconhecimento de que existem princípios fundamentais que encontram lastro nos mais variados campos de investigação. Para além do facto de que a Ciência sempre funcionou como catalisadora dos mais diversos conhecimentos. Como o nosso foco são as Ciências Sociais, vamos mencionar algumas das teorias transversais que ajudam a demonstrar que a perspetiva de rede pode ser aplicada em outros contextos.

\section{CONSTRUÇÃo DE IDENTIDADES}

A potência da alteridade é o que sociólogos como Viveiros de Castro (2002) e Stuart Hall (2000) chamam ao processo de construção da identidade através do contacto direto com o outro. As noções de subjetividade nascem no momento em que nos defrontamos com diferentes perspetivas. É deste modo que as identidades de povos e nações são socialmente construídas (Ashmore, Jussim \& Wilder, 2001). Viveiros de Castro procura explicitar o seu conceito com o exemplo da questão do eu dentro das comunidades ao afirmar que "se penso, então também sou o outro" (2010, p. 117).

O que os autores claramente procuram afirmar é que existe uma teia de relações que são criadas pelo indivíduo, no momento em que este procura definir a sua identidade. Atendendo ao que afirmámos anteriormente - que qualquer relação de interdependência pode ser analisada como uma rede -, estamos a dizer, em última instância, que a análise de rede permite não só a compreensão de um determinado fenómeno, como também, e essa é a conclusão da linha de raciocínio iniciada anteriormente, a análise da construção das identidades dos seus participantes. Na medida que a unidade básica de análise de rede são as díades (ligação entre pelo menos dois indivíduos), a construção 
das identidades dá-se numa negociação de valores entre os atores dentro de uma rede, que pode ser descrita através de princípios da Ciência das Redes.

É importante frisar que a complementaridadede métodos éo ideal numa investigação com este escopo. Tanto é que os conceitos usados para explicar as dinâmicas sociais também serão os mesmos usados para compreender as regularidades encontradas nas redes como a lei de potência de Barabási (1999) ou o caracter dinâmico e instável das redes de Watts e Strogatz (1998).

\section{CApital Social}

Outro exemplo disso é a forma como a influência segue um padrão que pode ser descrito na forma de rede. Foucault (2004) discutia a microfísica do poder, mas deixava claro que essa teia de influências é tecida em conjunto e nunca no vácuo. O poder social hoje em dia não reside apenas nos indivíduos ou nas instituições democráticas, mas também na estrutura que possibilita a sociedade como um todo. Para compreender este fenómeno, podemos adotar dois focos diferentes: usar a análise de rede para tentar compreender as relações entre os atores dessa rede ou procurar correlações entre as características atributivas de cada um dos atores, na tentativa de explicar as suas ações.

Falamos em relações de poder e influências, porque estes são dois conceitos que não podem ser esquecidos quando olhamos para uma rede social e a tentamos compreender. Inúmeros estudos têm procurado responder à questão de saber como a influência se demonstra nas redes (Huffaker, 2010; Meyerowitz, 1999), seja através do capital social que determinados atores adquiriram (Bourdieu, 1986), seja através da construção de comunidades imaginadas de partilha (Anderson, 1991), ou seja, ainda, através das forças dos laços fracos (Granovetter, 1983). Este último aspeto é apontado como uma das principais teorias que impulsionaram a perspetiva de rede.

\section{TEORIA DA FORÇA DOS LAÇOS FRACOS}

Um exemplo de abordagem distinta da análise de rede em relação às metodologias mais tradicionais das Ciências Sociais está relacionado com a forma como as redes são construídas e evoluem ao longo do tempo. Granovetter (1983) defendia que laços sociais fortes teriam reflexo numa redundância da informação que circula dentro de um determinado grupo ou comunidade trazendo, por conseguinte, estabilidade à rede. Porém, sendo de conhecimento que as redes são dinâmicas, podemos encontrar alterações na estrutura inicial de uma comunidade quando uma informação nova é trazida para dentro desse grupo. Essa informação geralmente é passada através dos laços mais fracos, ou seja, conhecidos que não partilham o mesmo nível de conhecimento mútuo dos outros. $\mathrm{Na}$ análise de rede, este conceito teve expressão na teoria de que as pessoas a quem alguém está conectado e a intensidade dessas conexões são determinantes no acesso a diferentes recursos. A intensidade das conexões como também a sua direcionalidade são dois conceitos nativos da análise de rede. 


\section{OS BURACOS ESTRUTURAIS}

O buraco estrutural é outra importante teoria que levou à formulação de um conjunto de conceitos como o de centralidade e posição do ator dentro de uma rede. Se numa rede com três elementos dois deles não tiverem ligação direta entre si ficam dependentes da intermediação de um terceiro - segundo Burt (1987) estamos diante de um buraco estrutural. Os buracos estruturais e a força dos laços fracos são importantes conceitos que ajudam a explicar o desenvolvimento de uma rede. Na tentativa de calcular tais abordagens, Freeman (1979) desenvolveu algumas medidas de centralidade tais como as medidas de intermediação, proximidade e grau, que traduzem esses conceitos para a análise de rede.

A necessidade de recorrer a métricas para caracterizar determinados atores é frequentemente apresentada como negativa em argumentações variadas que convergem num ponto - estamos perante ferramentas com interesse meramente quantitativo. Se bem que é verdade que estaremos a quantificar as relações encontradas dentro de uma determinada comunidade, em última instância o que interessa ao investigador é perceber as dinâmicas ali envolvidas.

Podemos concluir que explicar um fenômeno através da análise de rede faz com que o investigador assuma de antemão algumas perspetivas teóricas. São estas perspetivas que não podem ser ignoradas durante a leitura dos dados e representam um breve sumário do que foi até aqui discutido:

1. Todos os dados relacionais podem ser traduzidos numa rede, já que as redes são estruturas de interdependências (Wasserman \& Faust, 1994).

2. Toda a nossa organização social está assente em redes estruturais que foram estabelecidas previamente (Durkheim, 1996).

3. Por conta das influências sociais, as redes nunca são estáticas. Estamos a trabalhar com retratos temporários de um determinado acontecimento. As influências traduzem-se nas dinâmicas de poder (Barabási \& Albert, 1999; Watts \& Strogatz, 1998).

4. O capital social talvez seja o principal elemento que explica as relações de poder existentes dentro de certas comunidades (Recuero, 2009; Wellman, Hasse, Witte \& Hampton, 2001).

5. Por último, vale ressaltar que o comportamento de certos grupos será sempre a soma dos fatores acima mencionados (Watts, 2009).

Num estudo anterior, propusemos que a interação social assumia a forma de um fractal (Conrado Filho \& Santos, 2015). Agora percebemos que o fractal nada mais é do que uma forma bastante complexa de estruturar uma dada rede. Não importando o formato que essa estrutura possa vir a ter (seja ela fractal, espiral, ou um simples organograma), estaremos sempre a descrever o comportamento dos indivíduos como uma rede de ligações, até porque o formato de uma rede é apenas incidental às suas dinâmicas no momento da coleta dos dados. 


\section{ANÁlise de REde NAS CiÊnCias Sociais: Modelos E ABordagens}

Discutidos os conceitos e algumas perspetivas de rede existentes, importa perceber de que forma podem ser operacionalizados no âmbito de uma investigação em análise de rede. Antes de mais, é necessário estabelecer de que forma será a rede interpretada. Se será levada em consideração a sua totalidade ou apenas a posição pessoal de um determinado ator (ou como o chamaremos aqui, ego).

Molina (2009) propõe dividir estas duas visões entre modelos de abordagens estruturalistas e formalistas, no que divergiremos em termos de nomenclatura, mas não da ideia a ser defendida, já que as duas terminologias levam, em termos teóricos, a sobreposições concetuais. Para isso, basta irmos à definição de estruturalismo tal como defendida por Lévi-Strauss (1949). Segundo este, o conceito de estrutura social está associado às noções ou categorias universais da cultura e da linguística. Ou seja, o não atomismo, mas a compreensão das relações na sua totalidade e não pelas partes. Neste sentido, a forma das estruturas é preponderante aos elementos que a compõem.

O formalismo está associado às artes, matemática e filosofia, enfatizando a forma sobre o conteúdo (Erlich, 1973). Em última instância, observar a estrutura e a forma de uma rede são conceitos que se sobrepõem e, por isso mesmo, redundantes.

Por conta dessa divergência, adotamos a nomenclatura macro, ou sociocentrada, e micro, ou egocentrada, para indicar formalistas e estruturalistas, respetivamente, dentro da análise de rede. No fundo, este nosso diferendo com Molina está mais ligado à forma do que ao conteúdo, já que concordamos com as definições dos dois modelos de abordagens apresentados.

\section{MODELO DE ABORDAGEM MACRO (SOCIOCENTRADA)}

$\mathrm{Na}$ abordagem macro, ou sociocentrada, põe-se enfâse no todo e não apenas nos atores que compõem a rede. Garton, Haythornwaite e Wellman fornecem uma descrição mais precisa ao afirmar que as abordagens macro

consideram a totalidade da rede baseada em algum critério de fronteira populacional tal como as organizações, os departamentos, os clubes ou o parentesco. Esta abordagem considera tanto a ocorrência como a não ocorrência de relações entre todos os membros da população. Uma abordagem sociocentrada descreve os laços de todos os membros da comunidade com todos os outros $\left(2006, \int 20\right)$.

Em termos práticos, isto significa que ao olhar para uma comunidade interessa ao investigador ter em conta a sua totalidade e calcular as medidas de centralidade de toda a rede.

Um dos aspetos importantes na análise de rede é perceber o quão densamente conectada está determinada comunidade. Essa medida só pode ser calculada se for tomado como referência todo o grupo. Deste modo, é possível identificar buracos estruturais e atores em posições dominantes (que, de acordo com Lemieux e Ouimet (2012), podem ser dominante, semi-dominante, subdominante, dominado, sub-dominado e isolado). 
É importante referir que estas leituras só fazem sentido quando há interesse em perceber a rede na sua totalidade. Um exemplo bastante comum na área da comunicação é a análise de dados dos média sociais como o Twitter. Na leitura de dados que se faz de eventos dessa rede, é de extrema importância perceber que atores se destacaram e influenciaram a sua dinâmica. Esse tipo de leitura só poderá ser realizada se adotarmos uma perspetiva macro, sendo que a importância relativa de um determinado ator está diretamente relacionada com a sua posição dentro da rede.

Outra forma de se conceber uma explicação para uma abordagem sociocentrada é através das medidas de centralidade. Uma das maneiras mais imediatas de se abordar uma base de dados é procurar os elementos de destaque na rede através das medidas de centralidade (intermediação, proximidade e vetor próprio, por exemplo). Estas medidas apontam os atores com maior destaque em determinada função. Barabási (2016) afirma que não é difícil perceber que numa rede nem todos os atores possuem o mesmo destaque. A vantagem desta abordagem é a de desvelar quem são os atores em posições privilegiadas dentro de uma estrutura e, com isso, apontar caminhos ou hipóteses sobre a forma como essa rede funciona. É importante ressaltar que as medidas de centralidade servem para indicar a presença de relações de relevo.

Obviamente que quando esta abordagem foi concebida ainda não se tinha acesso às ferramentas de coleta de dados automáticas, como é o caso dos scripts que, em contacto com as API (Application Programming Interface) de plataformas como Facebook ou Twitter, são capazes de produzir redes com milhares de elementos em simultâneo. Estes processos de Big Data dão novo significado e relevo às abordagens sociocêntricas.

\section{MODELO DE ABORDAGEM MICRO (EGOCÊNTRICAS)}

Quando o interesse de investigação recai sobre o indivíduo (ego) e as relações que este desenvolve dentro de uma determinada rede, estamos diante de uma abordagem micro ou egocêntrica. Mais uma vez, recorremos a Garton et al. para definir este modelo:

uma das abordagens considera as relações relatadas pelo indivíduo. Estas redes egocêntricas (ou pessoais) fornecem uma visão ptolemaica das redes desde a perspetiva das pessoas (egos) no centro das suas próprias redes. Os membros da rede são definidos em função da sua relação específica com o ego. (2006, \19)

Como se percebe, esta abordagem está interessada nas ligações individuais de um determinado ator e no modo como essas relações ajudam a definir o seu comportamento. Os outros atores dessa rede são encarados como elementos que ajudam a definir o ego, não por conta dos seus atributos individuais, mas pela relação que estabelecem.

Esta abordagem foi durante anos a mais popular, pelo facto de ser mais facilmente construída. Baseia-se em grande parte no relatório pessoal que o ego fornece das suas ligações sociais. Neste caso específico, por exemplo, não existe necessidade de calcular medidas de centralidade para toda a rede pelo facto de que as únicas relevantes são as 
estabelecidas diretamente entre o Ego e os outros. Nesse sentido, para as redes egocêntricas não há interesse em saber se existe relação entre os outros elementos da rede. Um exemplo disso pode ser expresso na seguinte forma: sendo $A$ o nosso ego e sendo $B$ e C os outros que compõem a rede de ligações do ator $A$, não me interessa saber se $B$ e $C$ estão conectados e qual o tipo de relação que podem ter.

$\mathrm{Na}$ Antropologia, este tipo de análise serve para comparar diferentes redes micro e depois perceber a sua relação com a perceção que dela fazem os seus membros; a partir desta comparação podem fazer-se inferências sobre a real configuração social do grupo.

Os dados são coletados através da observação direta, da realização de entrevistas ou da aplicação de inquéritos aos participantes, numa lógica de bola de neve.

\section{MODELAÇÃo EM BLOCO [BLOCKMODELING]}

As modelações em bloco (ou modelos reduzidos) são aplicadas quando se pretende colapsar uma rede complexa em busca de um denominador comum. Este tipo de análise foi primeiro desenvolvida por Lorrain e White (1971), na tentativa de agregar atores que possuíam funções estruturais equivalentes dentro de uma rede. Nesta abordagem, pode partir-se tanto de um modelo micro, quanto macro (mais comum), sendo o mais importante a definição dos papéis desempenhados por cada um dos atores envolvidos.

Desse modo, interpretamos a rede não como um conjunto de atores individuais, mas antes como sendo composta por um conjunto de papéis que são desempenhados para a sua manutenção. A unidade básica de análise deixa de ser o ego e passa a ser o conjunto de atores que desempenham função semelhante.

É bem documentado que os atores que desempenham papéis estruturais semeIhantes tendem a dar respostas muito parecidas, quando confrontados com os mesmos tipos de situações (Burt, 1987).

Outro modo de se conceber a modelação em bloco é o de partição da rede, de acordo com critérios bem definidos. É importante distinguir entre a modelação em bloco por estruturas equivalentes, como foi acima mencionado, e a modelação em bloco por equivalência regular. De acordo com Doreian, Batagelj e Ferligoj (2005), este tipo de modelo engloba um conjunto de procedimentos empíricos e é baseado na noção de que as unidades dentro de uma rede podem ser agrupadas desde que apresentem alguma equivalência em termos definidos de antemão. Desse modo, podemos encarar a questão das equivalências ou como sendo diferentes unidades que apresentam o mesmo padrão de ligação com os mesmos atores ou como sendo as diferentes unidades que apresentam o mesmo padrão de ligação, mas com atores também diferentes entre si (Faust, 1998).

Um exemplo básico poderia ser o seguinte: dentro de uma empresa, o conjunto dos atores $A$, B e C são supervisores num dado departamento. O departamento ainda é composto pelos atores $\mathrm{D}, \mathrm{E}, \mathrm{F}$ e G. Ao partir a rede em blocos, num dos blocos teremos os supervisores e no outro teremos os restantes funcionários. Isto porque os atores $A, B$ e $C$, apesar de diferentes, estabelecem o mesmo tipo de relação com os mesmos atores $D, E, F$ e $G$. 
O outro modo de construir o modelo reduzido dessa mesma rede seria imaginarmos diferentes departamentos, onde cada uma das chefias estabelece ligações especificadas com os funcionários, como descrito em cima no texto. Obviamente que as chefias dos restantes departamentos não desenvolvem relações diretas com o mesmo conjunto de funcionários. Desse modo, apesar de diferentes, a equivalência ainda pode ser realizada na medida em que a relação supervisor-funcionário continuará a ser a mesma, independentemente do departamento em que se encontram. Resulta assim claro que quando falamos em analisar redes podemos estar a falar num espectro alargado de tipologias e, relativamente a cada uma delas, será possível adotar diferentes estratégias de enquadramento, coleta e preparação dos dados.

Assim sendo, o correto enquadramento da pergunta de partida determinará o tipo de abordagem ou modelo utilizado na sua interpretação. Esta ideia vale tanto para o caso dos estudos de eventos online como para o estudo das formas de organização de uma determinada comunidade ou grupo. Estabelecida esta noção, resta reconhecer que a única diferença residirá nas formas de coleta destes mesmos dados que, em alguns casos, será automatizada e, em outros, manual. O objetivo final será sempre o de construir uma matriz que possibilite a utilização da teoria dos grafos e das teorias de rede para explicar o objeto em questão.

\section{LIMITAÇõES DA ANÁLISE}

Uma das principais limitações da análise de rede acontece logo no momento da coleta de dados. Sobre a coleta manual é fácil perceber como esta é realizada: através de questionários, entrevistas ou mesmo observação não-participante de um conjunto de atores. Como, por exemplo, o comportamento dos alunos dentro de uma escola, as influências dentro de um escritório de trabalho, as relações de amizade entre músicos de diferentes bandas, para citarmos apenas alguns exemplos.

Entre as vantagens deste tipo de coleta destaca-se a fiabilidade dos dados, já que, antes de serem colocados na base de dados, estes são verificados pelo investigador (um problema bastante comum para quem trabalha com hashtags e palavras-chave nos média sociais, por exemplo). Os dados coletados manualmente já estão praticamente filtrados e prontos para serem analisados. A principal limitação aparente dos dados, e fica sublinhado o aparente, é o alcance ou a profundidade que uma coleta manual pode fornecer, dependendo do tamanho e da complexidade da rede observada.

É importante que sejam definidos à partida os limites da coleta que se pretende fazer. Quando falamos de uma abordagem egocêntrica, por exemplo, facilmente se cai na tentação de crer que uma identificação exaustiva de toda a rede é uma tarefa exequível. Se nos lembrarmos que as redes são compostas tanto por ligações diretas como por ligações indiretas, percebemos que o potencial de crescimento de uma rede é ilimitado, cabendo, portanto, ao investigador definir até que profundidade pretende coletar para avaliar determinado objeto.

$\mathrm{Na}$ outra ponta do espectro temos as coletas automáticas, feitas através dos média sociais. Estas coletas acarretam num conjunto de estratégias diferentes para superar os 
mesmos obstáculos mencionados anteriormente. Escolhida a realidade a ser observada, resta perceber as possibilidades que cada plataforma providencia, sendo que cada uma das plataformas traz consigo um conjunto de limitações de ordem técnica. A coleta automática deverá sempre ser feita através de scripts ou aplicações que permitam o contato com a API da plataforma em questão. Para além disso, estas API existem para controlar e limitar o acesso a alguns dos dados existentes - o que nos poderia levar a uma discussão exaustiva sobre quem detém os direitos sobre os dados que produzimos online (Bruns, 2016).

De forma a exemplificar algumas das limitações e vantagens da coleta, vamos abordar as duas maiores plataformas de média sociais: o caso Twitter e Facebook.

O Twitter já possui um vasto lastro académico com pesquisas feitas através do serviço de microblogging. Algumas das vantagens são o facto de todas as publicações serem públicas por definição, o próprio serviço já organiza os temas mais relevantes e permite a coleta de um determinado volume de dados. O grande senão advém da sua limitação sociodemográfica não tão representativa. Como resume Blank:

os utilizadores britânicos do Twitter são mais jovens, mais ricos e com mais escolaridade do que os utilizadores de internet em geral, que por sua vez são mais jovens, mais ricos e com mais escolaridade do que a população britânica offline. Os utilizadores norte-americanos do Twitter são também mais jovens e mais ricos que o resto da população, mas por outro lado já não apresentam mais escolaridade. Os utilizadores do Twitter são desproporcionalmente membros de uma determinada elite de ambos os países. Os utilizadores do Twitter também se diferenciam de outras comunidades online no que toca as suas atividades e atitudes. Estes enviesamentos e diferenças têm importantes implicações nas pesquisas que são feitas através do Twitter. (2016, p. 679)

Se levarmos ainda em consideração realidades como a portuguesa, em que o Twitter tem um público muito menor por comparação com outras redes, como o Facebook, começamos a perceber que tipos de imposições estamos a colocar aos nossos dados. O estudo dessa realidade não é invalidado apenas por isso, mas é preciso conhecer o contexto de análise em questão antes de começar a explicá-lo.

O Facebook é o mais popular dos média sociais existentes, com um total de utilizadores que ultrapassa os 2 mil milhões. É de se pensar, por isso, que talvez apresente as melhores oportunidades de leituras sociais. O facto é que, sendo uma plataforma com um modelo de negócio mais agressivo (e eficiente), dificulta e limita o acesso a dados, alegando a proteção da privacidade dos seus utilizadores (em 2018 ficámos todos a perceber melhor a fragilidade deste argumento). Enquanto que no Twitter temos acesso ao fluxo de conversação, no Facebook somos limitados às páginas e grupos públicos. Mesmo a qualidade do tratamento interno dos dados pelo Facebook aparenta ter algum problema, desde que alguns anunciantes repararam que o público-alvo dos seus anúncios está a ser erradamente identificado. Temos aqui, mais uma vez, um exemplo da forma como as barreiras técnicas acabam por prejudicar a coleta de dados. 
Entretanto, as coletas automatizadas sofrem ainda de um outro problema, independentemente da plataforma escolhida: a filtragem. A maioria das coletas em conjuntos de dados alargados faz-se com palavras-chave, muitas vezes ambíguas, que implicam um trabalho posterior de filtragem e de 'limpeza' antes da análise.

Uma outra limitação que podemos apontar, e que não está ligada propriamente às técnicas de coleta, diz respeito à dificuldade de comparação entre várias redes. Apesar de a investigação em análise de rede estar ancorada em princípios matemáticos, a comparação entre diferentes redes, que correspondem a fenómenos diversos, deve ser feita com enorme prudência. Um exemplo simples diz respeito às medidas de centralidade que são calculadas nas abordagens macro. Como cada um dos valores diz respeito a uma realidade distinta, o que pode parecer um elevado valor de intermediação, para ficarmos apenas por uma das mais populares medidas de centralidade em análise de rede, pode não ter o mesmo significado numa rede que apresenta densidade ou estrutura diferente. Com isso não queremos afirmar que as comparações estão inviabilizadas, mas devem antes ser consideradas dentro de grupos ou comunidades muito semelhantes entre si, como no caso das redes egocentradas (abordagem micro).

\section{Conclusão}

A análise de rede pode sempre ser usada para compreender um determinado fenómeno ou comportamento, como também, numa perspetiva utilitarista, para perceber de que modo se pode racionalizar os recursos na tentativa de maximizar a eficiência de uma rede. Esta última ideia é defendida por Rod Meadows (1983), por exemplo, que argumenta que para que os publicitários possam compreender o comportamento dos seus clientes é importante seguir os passos dos utilizadores nos seus mais diversos recantos, mapeando as suas interações. Tarefa que se tornou mais fácil com a difusão da internet e dos métodos digitais.

Obviamente, as análises de rede não apresentam respostas para todos os tipos de contextos. Kozinets (2010) afirma que, para se compreender experiências de vida de uma determinada comunidade online, as análises de rede não bastam, propondo antes a utilização das técnicas de netnografia. Entretanto, para os contextos em que se pretende analisar o modo como os atores de uma determinada comunidade se comportam e influenciam mutuamente, a análise de rede oferece a abordagem mais adequada, já que esta prima pela informação relacional que, em última instância, pode sempre significar a observação da forma como os atores moldam ou constroem as suas próprias identidades (White, 2014).

O potencial que os média sociais trouxeram para a análise e compreensão de uma parte importante do nosso comportamento social foi o que possibilitou em larga escala a popularização e o uso dessa perspetiva. Entre os claros benefícios que a perspetiva de rede apresenta, encontra-se a possibilidade de identificar padrões no comportamento das estruturas sociais e, assim, prever com alguma acuidade situações que dali possam advir. 
Outra mais-valia é a capacidade de melhor conhecer e explorar os limites da comunicação, de forma a tentar torná-la mais eficaz e democraticamente distribuída. Como afirma Fuchs (2015), a ideia de que os média sociais por si só trouxeram no seu encalço o fortalecimento da democracia é uma posição um tanto quanto questionável, na medida em que se observa os limites a que estão sujeitos.

Entre prós e contras, é de se reconhecer que a análise de rede (ou a Ciência das Redes, como preferem alguns autores) trouxe um conjunto de mecanismos e ferramentas que permitem leituras que são essenciais para as Ciências Sociais e o reconhecimento da sua flexibilidade de utilização em diferentes contextos só potencia ainda mais a sua importância.

\section{REFERÊNCIAS BIBLIOGRÁFICAS}

Amaral, I. (2012). Participação em rede: do utilizador ao "consumidor 2.0" e ao "prosumer". Comunicação e Sociedade, 22, 131-147. doi: 10.17231/comsoc.22(2012).1278

Anderson, B. (1991). Imagined communities: reflections on the origin and spread of nationalism. Londres: Verso.

Ashmore, R., Jussim, L. \& Wilder, D. (2001). Social identity, intergroup conflict, and conflict reduction. Oxford: Oxford University Press.

Barabási, A.-L. (2002). Linked. Cambridge, Massachusetts: Perseus Publishing.

Barabási, A.-L. (2016). Network science. Cambridge: University Press.

Barabási, A.-L. \& Albert, R. (1999). Emergence of scaling in random networks. Science, 286(5439), 509-512. doi: $10.1126 /$ science.286.5439.509

Blank, G. (2016). The digital divide among twitter users and its implications for social research. Social Science Computer Review, 35(6), 679-697. doi: 10.1177/0894439316671698

Borgatti, S., Mehra, A., Brass, D. J. \& Labianca, G. (2009). Network analysis in the social sciences. Science, 323(5916), 892-895. doi: 10.1126/science.1165821

Bourdieu, P. (1986). The forms of capital. In J. Richardson (Ed.), Handbook of theory and research for the sociology of education (pp. 241-258). Nova lorque: Greenwood Press.

Bruns, A. \& Burgess, J. (2016). Methodological innovation in precarious spaces: the case of Twitter. In S. Robert, H. Snee, C. Hine, Y. Morey \& H. Watson (Eds.), Digital methods for social science (pp. 17-33). Londres: Palgrave Macmillan.

Buchanan, M. (2002). Nexus: small world and groundbreak science of networks. Nova lorque: Norton.

Burt, R. S. (1987). Social contagion and innovation: cohesion versus structural equivalence. American Journal of Sociology, 92, 1287-1335. doi: 10.1086/228667

Conrado Filho, F. \& Santos, L. A. (2015). Second screen and information: history, definition and clues for the future. Comunicação e Sociedade, 28, 211-227. doi: 10.17231/comsoc.28(2015).2278

Doreian, P., Batagelj, V. \& Ferligoj, A. (2005). Generalized blockmodeling. Nova York: Cambridge University Press. 
Durkheim, E. (1996). O suicídio. Lisboa: Editora Presença.

Erlich, V. (1973). Russian formalism. Journal of the History of Ideas, 34(4), 627-638. doi: 10.2307/2708893

Faust, K. (1988). Comparison of methods for positional analysis: structural and general equivalences. Social Networks, 10, 313-341. doi: 10.1016/0378-8733(88)90002-0

Foucault, M. (2004). Microfísica do poder. Rio de Janeiro: Graal.

Fuchs, C. (2014). Social media: A critical introduction. Londres: Sage.

Garton, L., Haythornthwaite, C. \& Wellman, B. (1997). Studying online social networks. Journal of ComputerMediated Communication, 3(1), s/p. doi: 10.1111/j.1083-6101.1997.tbooo62.x

Granovetter, M. (1983). The strength of weak ties: a network theory revisited. Sociological Theory, 1, 201-233. doi: $10.3390 /$ soc2020027

Hall, S. (2000). The spectacle of the 'other'. In S. Hall (Ed.), Representation: cultural representations and signifying practices (pp. 236-237). Londres: Sage.

Huffaker, D. (2010). Dimensions of leadership and social influence in online communities. Human Communication Research, 36, 593-617. doi: 10.1111/j.1468-2958.2010.01390.x

Kozinets, R. (2010). Netnography. Doing ethnographic research online. Thousand Oaks: Sage Publications.

Lemieux, V. \& Ouimet, M. (2012). Análise estrutural das redes sociais. Lisboa: Instituto Piaget.

Lévy-Strauss, C. (1982). As estruturas elementares de parentesco. Petrópolis: Vozes.

Lorrain, F. \& White, H.C. (2010). Structural equivalence of individuals in social networks. The Journal of Mathematical Sociology, 1(1), 49-80. doi: 10.1080/0022250X.1971.9989788

Meadows, R. (1983). They consume advertising too. Admap, 19, 408-413.

Meyrowitz, J. (1999). Understandings of media. ETC: a review of general semantics, 56(1), 44-52.

Molina, J. L. (2009). Panorama de la investigación en redes sociales. REDES - Revista hispana para el análises de redes sociales, 17(11), 235-256. doi: 10.5565/rev/redes.383

Moreno, J. L. (1934). Who shall survive? A new approach to the problem of human interrelations. Washington: Nervous and mental disease Publishing Co.

Recuero, R. (2009). Redes sociais na internet. Porto Alegre: Sulina.

Serrat, O. (2017). Social network analysis. In O. Serrat (Ed.), Knowledge solutions (pp. 39-43). Singapura: Springer. doi: 10.1007/978-981-10-0983-9-9

Viveiros de Castro, E. (2002). A inconstância da alma selvagem - e outros ensaios de antropologia. São Paulo: Cosac \& Naify.

Viveiros de Castro, E. (2010). Encontros. Rio de Janeiro: Beco do Azougue.

Wasserman, S. \& Faust, K. (1994). Social network analysis: methods and applications. Cambridge: Cambridge University Press. doi: 10.1017/CBO9780511815478

Watts, D. \& Strogatz, S. H. (1998). Collective dynamics of 'small-world' networks. Nature, 393, 440-442. doi: $10.1038 / 30918$ 
Watts, D. (2003). Six degrees: the science of a connected age. Nova lorque: Norton.

Watts, D. (2004). The "new" science of networks. Annual Review of Sociology, 30(1), 243-270. doi: 10.1146/ annurev.soc.30.020404.104342

Wellman, B., Haase, A. Q., Witte, J. \& Hampton, K. (2001). Does the internet increase, decrease, or supplement social capital? Social networks, participation, and community commitment. American Behavioral Scientist, 45(3), 436-455. doi: 10.1177/00027640121957286

White, A. (2014). From the private to the public: online identity. In A. White (Ed.), Digital media and society: transforming economics, politics and social practices (pp. 26-42). Londres: Palgrave Macmillan. doi: $10.1057 / 9781137393630$

\section{NOTAS BIOGRÁFICAS}

Francisco Conrado Filho é Mestre em Comunicação pela Universidade do Minho (Portugal) onde é atualmente estudante de doutoramento. Tem-se dedicado a estudar as relações de permeabilidade entre a profissão jornalística e o jornalismo em si, com as novas ferramentas tecnológicas. Mais recentemente passou a estudar as mudanças nas relações de poder e as dinâmicas do fluxo de comunicação online a partir da análise de rede. Integra o grupo de investigação MODA - Monitoring Online Discourse Activity.

E-mail: franciscoconradofilho@gmail.com

Morada: Centro de Estudos de Comunicação e Sociedade, Universidade do Minho, Campus de Gualtar, 4710-057, Braga - Portugal

Luís António Santos é Professor Auxiliar no Departamento de Ciências da Comunicação da Universidade do Minho e investigador do Centro de Estudos de Comunicação e Sociedade (CECS) desde 2000, interessando-se por áreas como o Jornalismo e os processos de digitalização, novos formatos sonoros e regulação da internet. Foi jornalista de imprensa e rádio durante 10 anos - Jornal de Notícias, Rádio Press/TSF, Diário de Notícias, BBC World Service - e tem um Mestrado em Política Internacional, pela School of Oriental and African Studies (SOAS) da Universidade de Londres, e um Doutoramento em Ciências da Comunicação pela Universidade do Minho. Foi membro de projetos de investigação internacionais nas áreas da regulação dos média e de novos formatos sonoros.

E-mail: d266o@ics.uminho.pt

Morada: Centro de Estudos de Comunicação e Sociedade, Universidade do Minho, Campus de Gualtar, 4710-057, Braga - Portugal

* Submetido: 30.11 .2017

* Aceite: 15.03.2018 